\title{
Innovative Design of Multi-Functional Computer Desk
}

\author{
Qiulei Du, Liai Pan* and Zixuan Cheng
}

Changchun University, Changchun, Jilin, 130022, China

\begin{abstract}
With the popularization and application of computer, the application of the computer desk is much higher. In order to meet the requirements of new features, its structure is also constantly changing. In this paper, the deficiencies of the current computer desk on the market have been focused on analysis. Structural design of the computer desk has been begun, and comfortableness of computer desk has been designed, in order to make it meet the requirements of ergonomics. After the design of computer desk, the structure was compact, shaping was beautiful, and it can make the user convenient and comfortable.
\end{abstract}

Keywords: Computer desk, ergonomics, model design.

\section{INTRODUCTION}

Along with the popularization of computers, computer desk applications is rising, therefore its structure is constantly changed and updated to meet new requirements. The survey found that many users when configuring computer, always carefully select, shop around and choose the most suitable for their own computers. But often ignore the importance of the optional computer desk. Many people at home do not have to buy a special computer desk, just casually with ordinary home instead of desks and chairs, the result over time, often backache, neck pain, fatigue is not that affect vision, so that the configuration of a sets right computer desk is quite necessary. On the other hand, along with the improvement of people's aesthetic sense, and now people of city began to have a new computer desk requirements - personality style, complete functions. This paper began with structure design of computer desk, focusing on from comfort to functionality design of it and striving to make it accord with ergonomic requirements, and strive to make the computer desk and ergonomic requirements, so as to meet the aesthetic requirements.

\section{MARKET RESEARCH OF THE COMPUTE DESK}

\subsection{Classification of The Computer Desk on The Market}

\section{(1) Cabinet computer desk}

The main part of this computer desk is made of wood. Its structure is similar to the cabinet, strong and stability, but it is heavier, moving up very arduous. It modeling is more single, and is the straight edge right angles, square founder.

(2) Posture computer desk

This kind of computer desk is made of wood, also is made of wood and steel. Its structure is similar to shelves, whose block-like part is made of wood, whose vertical bracket parts are made of wood or steel tube. In modeling, this computer desk has some changes than the former.

\section{(3) All steel computer desks}

This kind of computer desk is all made of steel. It is very strong and very stable, but it is very heavy, which is moved very inconveniently. In the majority with quadrate modeling, few people use this computer desk now.

\section{(4) Glass computer desk}

This kind of computer desk is made of glass and steel pipe. Good transparency and sturdy glass reinforced plastics has been used, which is combined with high brightness tube appear beautiful fashion.

\section{(5) Marble computer desk}

In the summer, the computer desk can give a person a kind of cool feeling. Its unique natural texture make fans feel hospitable, fondle admiringly, but its price is more expensive.

\subsection{Computer Desk's Influence on Children}

In view of the category of computer desk, for a primary school in the city the students of grade 1-5, a sampling survey of the computer desk usage has been made. With the cooperation of the teacher at the school, in each grade sampling 20 copies, 87 valid questionnaires have been gotten finally. The survey's result has been shown in Fig. (1). When children used, seemingly ordinary computer desk could cause some damage to the body. Most of the students are in a safe, but it is not comfortable state. This is because the traditional design concept in our country attaches great importance to the safety, the protection of user and user), but ignores the users comfort. It easily makes users very easy to fatigue. It is a typical example to sitting on the chair in the "correct" action. Although this movement is very safe, but also to cultivate elementary student's discipline, but after a long time, students can easily fatigue. 


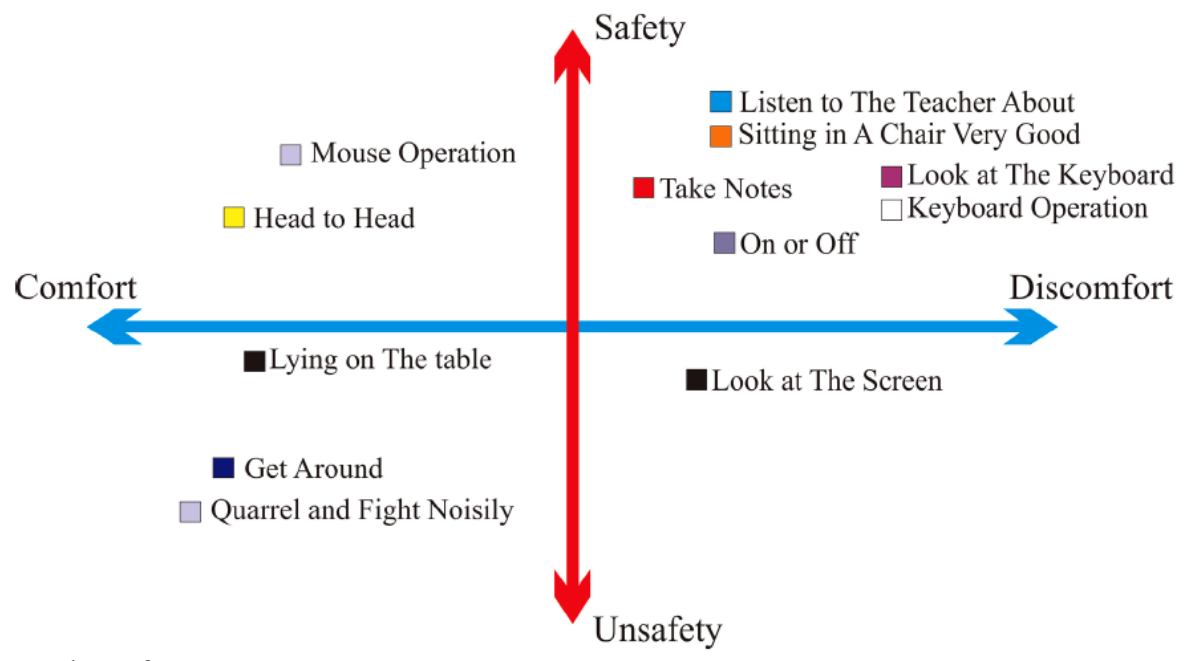

Fig. (1). Matrix of safety and comfort.

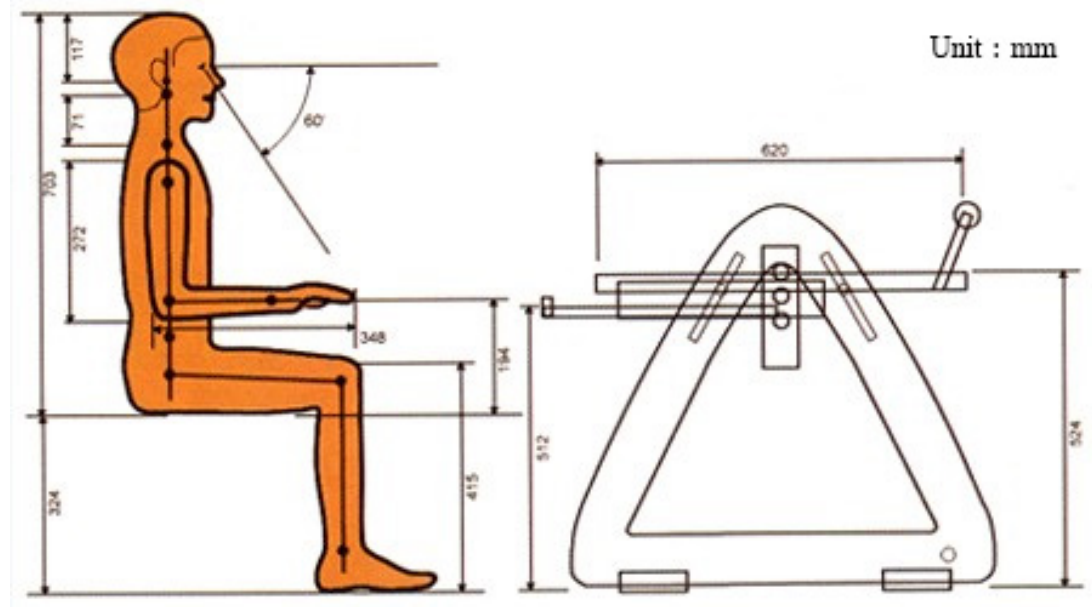

Fig. (2). Sizes of boys' body engineering.

And if the size of the computer desk is not reasonable, it may cause bad influence to student's spinal cord development. So, the design decided to give full consideration to the related knowledge of human body engineering. Through reasonable arrangement of dimension and space, a more comfortable space for operation has been provided; and avoided the occurrence of similar situations.

Display the turntable is very necessary. What now we advocate is people-centered product design. So on the one hand, the design of computer desk should been the center as people' protection; on the other hand, design of the computer desk is not a simple product design, must also take into account the environment and space design. A computer manmachine size what nine years old boy works is shown in Fig. (2). In the Fig. (2), the medium size to the 50th percentile is the basis.

\subsection{Some Problems of The Computer Desk on The Mar- ket at Present}

\section{(1) Lack of reasonable support}

When people are in computer operation, position sitting is forward. It can cause an unstable state that the back of the man is from the back of the chair, the arm are out of the chair, chair face only support person's hips. People usually adopt the way of the palm of your hand to support to maintain a stable body and the support not only stability is bad, very easy to form excessive forward, hunched over adverse consequences, and they need the waist and back muscle in static tension force, thus increased the burden of muscle, back muscle strain. So, many computer operators can bear pain of the waist and back. When people operate the computer, due to lack of support for the elbow, elbow was hung in the operating position, and the upper arm and forearm need to keep a certain angle fixed position; muscles in humeral back, arm and wrist are in a static tension force. It is easy to cause fatigue.

\section{(2) Location of the host}

Should the host be on the desk or under the desk? The computer desk on the market at present basically has two locations. It is good in dust on the desk, and quieter under the desk. It is easy to use on the desk, more beautiful under the desk. Personal thought, when the host is close to display, heat dissipation is bad, and electromagnetic interference to each other, and radiation and sound of a host are bigger also. It is close to people on the desk, it is very adverse to health. So comprehensive consideration, and the next is better. 


\section{(3) Not convenient to remove}

Some are not suitable for computer and family. I think a mobile base is better, it is easy to drag with a handle, also doesn't use desktop box (common) on the new desk, or line is too short to insides out. Look clean but there is a hidden trouble, we should avoid it.

\section{(4) Color research}

The color of the computer desk should be is associated with master be fond of, But also should maintain its coordination with the colour of the indoor environment. It is not only to meet the needs of people physiology, but also meet the aesthetic needs of people [1]. Because the computer screen is bright, if the nature of work requires line of sight to switch back and forth between the screen and desktop file, in order to avoid the eyes error due to adapt to the light and shade of dispersing and attention, desktop color and screen color brightness contrast not too big, otherwise easy to cause visual fatigue. Desktop appropriate USES white, light blue, light grey, downy light, this also with the current household environment or phase modulation of light color coordination office environment [2].

\section{(5) Computer protection}

In design of many computer desks, the exterior factors has been only considered, the protection design of computer has been ignored. For example, display space of the chassis is not too close. If there is not enough space for heat dissipation and ventilation, computer mainframe is working for long time in high temperature, some part has been accelerated aging, a lot of damage of components has a direct relationship with this.

(6) Height, angle and visibility of the displays is not reasonable

The top of the display should not be higher than the level line of sight sitting; the bottom of the display should not be less than 40 degrees down the direction; the center of the display should be in a horizontal line of sight under $10^{\circ}$ $20^{\circ}$. The surface of display should maintain a certain slope in vertical with the line of sight of people. It seems that the horizontal host should not be on display. Distance between eyes and display should be in commonly $70 \mathrm{~cm}$, is an arm distance. If the improper place of the shortage of the computer desk or computer make the computer system can not meet the above parameters, it can produce adverse effect to human vision health.

\section{(7) Desktop space}

Most computer desks are square or straight edge right angles. These computer desks don't conform to the requirements of the machine, is used uncomfortable, and might even hurt the body. For users who have many computer accessories, computer desk seem to be "small", not put other devices, such as speakers, printer accessories, there is no special place. Design should be people-oriented, based on the user's specific situation. For business computer, $80 \%$ of the work has been done by keyboard, at home, $80 \%$ of the time is in the operation of the mouse. Unreasonable design of computer desk can lead to low back pain, neck muscle fatigue or strain, hand tendon sheath and decreased vision. From 1996 to 1996, Beijing labor health institute of occupa- tional disease prevention and control had investigated workshop homework personnel in the telecom industry computer, television, and newspaper laser typesetting. The results showed that $30 \%$ respondents wrist of neck shoulder syndrome in different degrees, has generally been declining eyesight. The Hong Kong institute of physical therapy has investigated 290 middle school students use of computers. The results showed that about $40 \%$ of the students were in pain musculoskeletal system, including low back pain, neck muscle fatigue or strain, hand tendon sheath, etc. According to a study at Cornell University in the United States, because the design of the school's computer workstation has little or no considerate of musculoskeletal development, sitting position of $40 \%$ of primary school children at risk of is not straight. In Japan, before 1971, standard height of the desk is $74 \mathrm{~cm}$. Due to a variety of occupational disease, Japan overhaul in 1971 , the office appliance standards. Male and female standard height of the desk are respectively is $70 \mathrm{~cm}$ and $67 \mathrm{~cm}$, thereby significantly reduced the incidence of fatigue. In the $\mathrm{UK}$, the current recommended desktop height is $71 \mathrm{~cm}$ only. But in our country, the height of computer desk, desk, desk is typically between $75 \mathrm{~cm}$ to $76 \mathrm{~cm}$, it is clearly too high. Therefore, based on the above reasons, the design of the computer desk strictly from the human body size in our country as the human body engineering design basis, a bold innovation has been made in use comfort, functionally, beautifully.

\section{SIZE COMPUTATION AND ANALYSIS OF COM- PUTER DESK}

According to references [3] to determine humancomputer size analysis, the main products is calculated as follows:

Desktop height is not too high nor too low, and therefore the need to use the stature percentiles $(50 \%)$ to calculate desktop height.

Desktop height: $1333 \times 7 / 17+30$ (functional correction amount $)+50$ (psychological correction amount $)=855$;

Desktop Length: 450 (keyboard length) +80 (correction amount) +180 (main chassis width) +40 (correction amount) $+550($ leg space $)=1300$;

Desktop Width: 400 (monitor thickness) +100 (functional correction amount) +100 (psychological correction amount) $=650$;

Under table space design should be used to calculate a large percentile. If table space is also bound for short people to choose a small percentile calculation assumptions, the space is too small, will feel big enough space, resulting in a sense of oppression.

Space under the table: $1884 \times 1 / 3+50$ (correction amount) $=680$;

Upper small distance away from desktop: 206 (psychological correction amount) +60 (correction amount) $=226$;

Place main chassis plate width: 180 (main chassis width) +120 (correction amount) $=260$.

Main dimensions of computer desk are shown in Table $\mathbf{1 .}$ 
Table 1. Main size of computer desk unit:mm.

\begin{tabular}{|c|c|c|c|c|c|}
\hline Desktop Length & $\mathbf{1 3 0 0}$ & Desktop Width & $\mathbf{6 5 0}$ & Desktop Thickness \\
\hline \hline mainboard length & 575 & mainboard width & 260 & mainboard thickness & 15 \\
\hline Keyboard length & 540 & Keyboard width & 565 & Keyboard thickness & turn table height \\
\hline small desktop length & 500 & small desktop width & 230 & 235 & iron pipe thickness under desktop \\
\hline drawer length & 400 & drawer width & table leg location & $\begin{array}{c}\text { shown in Fig. } \\
(3)\end{array}$ \\
\hline table leg height & 740 & table leg radius & the other boards all with thickness of 10 & \\
\hline
\end{tabular}

4. BOLTED CONNECTION CHECKS BETWEEN COMPUTER DESK SIDE AND SUPPORT PLATES, SLIDES AND KEYBOARD SUPPORT PLATE

\subsection{Bolt Group Design is Shown in Fig. (3)}
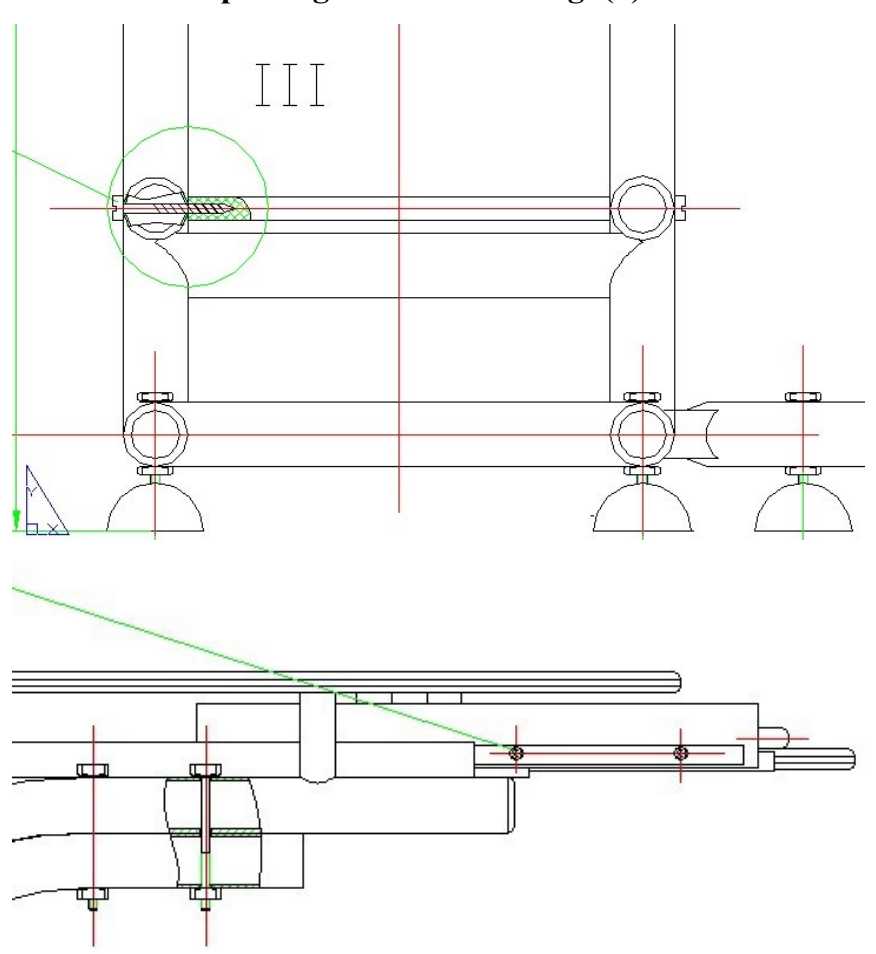

Fig. (3). Bolted connections between computer desk side and support plates, slides and keyboard support plate.

Structure design shown in Fig.3 is applied, number of bolts is 4 .

\subsection{Bolt Stress Analysis [4, 5]}

(1) Keyboard plate probably bear weight of $\mathrm{m}=6 \mathrm{~kg}$ weight, then total load is

$F_{\Sigma}=\mathrm{mg}=6 \times 9.8=58.8 \mathrm{~N}$

(2) Under the effect of total load $F_{\Sigma}$, screw group connection is effected by transverse force.

Transverse force $F_{\Sigma V}=F_{\Sigma}=58.8 \mathrm{~N}$
(3) Under action of axial force $F_{\Sigma V}$, joint face is possibly sliding chute connections, according to joint face sliding condition

$f\left(z F_{0}\right)-\frac{C_{m}}{C_{b}+C_{m}} F_{\Sigma h} \geq K_{s} F_{\Sigma v}$

by looking up the table data, coefficient of friction between faying surfaces can be reached as $\mathrm{f}=0.16$, and assign

$\frac{C_{b}}{C_{b}+C_{m}}=0.2$

Then

$\frac{C_{m}}{C_{b}+C_{m}}=1-\frac{C_{b}}{C_{b}+C_{m}}=0.8$,

assigning anti-skid factor as $K_{S}=1.2$,

Then each bolt pre-tightening force needed are as follows:

$F_{0} \geq \frac{1}{Z}\left(\frac{K_{s} F_{\Sigma v}}{f}\right)+\frac{C_{m}}{C_{b}+C_{m}} F_{\Sigma h}$

$=0.25 \times\left(\frac{1.2 \times 58.8}{0.16}+0.8 \times 0\right)=110 \mathrm{~N}$

(4) Total pulling force of the above screws is $F_{2}=F_{0}=110 \mathrm{~N}$.

$\phi=\arccos \frac{\left(z_{n 13}-z_{n 1}\right)}{L_{n}}$

\subsection{Confirmation of Screw Diameter [6]}

Screw material Q235is chosen, with performance rating of $4.6, \sigma_{s}=240 \mathrm{MPa}$, According to the table, safety factor $\mathrm{S}$ $=1.5$, allowable stress of screw material is $[\sigma]=\frac{\sigma_{s}}{S}=\frac{240}{1.5}$ $\mathrm{MPa}=160 \mathrm{MPa}$.

Diameter of screw dangerous section (thread path) is 
$d_{1} \geq \sqrt{\frac{4 \times 1.3 F_{2}}{\pi[\sigma]}}=\sqrt{\frac{4 \times 1.3 \times 110}{3.14 \times 160}}=1.09$

According to slot pan head self-tapping screws (GB/T5282-2000), thread nominal diameterdis3mm(minor diameter of thread $d_{1}=2.459 \mathrm{~mm}>1.09 \mathrm{~mm}$ )

\subsection{Required Pre-Tightening Force of Screw Check [7]}

Carbon steel screw, requiring

$F_{0} \leq(0.6 \times 0.7) \sigma_{s} A_{1}$

Known conditions are separately $\sigma_{s}=320 \mathrm{Mpa}$.

$A_{1}=0.25 d_{1}^{2}=\frac{1}{4} \pi \times 2.459^{2} \mathrm{~mm}^{2}=4.5 \mathrm{~mm}^{2}$

Pre-tightening force limit is taken:

$0.6 \sigma_{s} A_{1}=0.6 \times 240 \times 4.5 \mathrm{~N}=685 \mathrm{~N}$

and needed $F_{0}=110 \mathrm{~N}$, is far less than upper limit value, so requirements are met.

\section{INNOVATIVE DESIGN OF COMPUTER DESK SHAPE}

Industrial product design is to create a shape with a practical function, requires not only a function of its image has to adapt to needs of people work, meet people use, and performance requirements of style of its appearance, shape, style, atmosphere gives the United States feel and enjoy art, play beautify production and living environment to meet aesthetic requirements of consumer, and thus become spiritual and material modeling has two functions [8]. Industrial design is a product of commodity economy, which has the effect of stimulating consumption, industrial design so there is a new addition to simple use of a functional relationship between product and consumer outside. With social and economic development, attention of consumers has not only stay in quality of products and services, factors affecting consumer spending more product appearance, and product materials, colors. Enhance aesthetic concept of consumer, which requires industrial designers to meet this consumer psychology aesthetic requirements. Industrial product design principles to be as follows, namely the principle of innovation, aesthetic principle, feasible in principle, principle of reasonableness, practical principles, reliable principles and economic principles[9]. Multifunctional computer desk design should have following salient features:

(1) All supporting legs arc shape, forming a curve with an incomparable sense of beauty spatial mobility, simple and smooth lines highlight characteristics of product.

(2) streamlined desktop, bold design to break inherent size of market, is a natural product of innovative design.

(3) oval display turntable, attractive appearance, and arc shape of legs and sleek desktop echoes, to bring some products have an affinity with appeal.

\section{FUNCTION DESIGN OF COMPUTER DESK}

(1) Display turntable design

Due to advances in technology, current full for LCD computer monitors. If people want to change perspective of display will rotate back and forth, this will inevitably lead to a desktop monitor stand and wear. This design uses a rotary table oval display, easy-round rotating $360^{\circ}$, which will solve the problem.

\section{(2) Desktop to right lobe design}

As people use mouse when arm is basically a part of limbo, so it is bound to increase arm fatigue. To this end, the lower right corner on the desktop designed a circular lobes, for providing a support arm of platform, but also increased area of mouse to move, reduce arm fatigue, to solve the problem.

\section{(3) Printer support table design}

According to overall style computer desk, desktop design of the upper left corner of place to put printer, namely printer support units. Its streamlined shape and overall computer desk echoes, no prominent place because printer device and cause damage to the overall style computer desk.

Product design is the core of industrial design, and effective product modeling, simulation can quickly see the true effect of the product, can shorten the product manufacturing process some of the link, is advantageous to the products to market faster [10]. Combine to sum up the theoretical design of computer desk, using three-dimensional modeling software Rhino MAX on the $3 \mathrm{D}$ and $3 \mathrm{D}$ modeling simulation design, three design schemes as shown in Figs. (4-6).

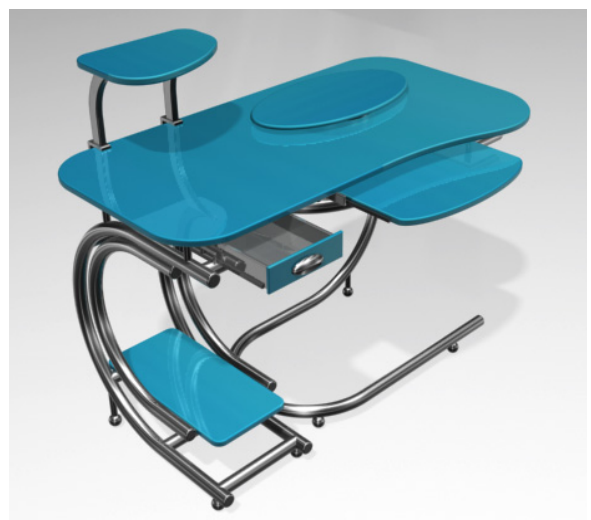

Fig. (4). Solution of blue glass

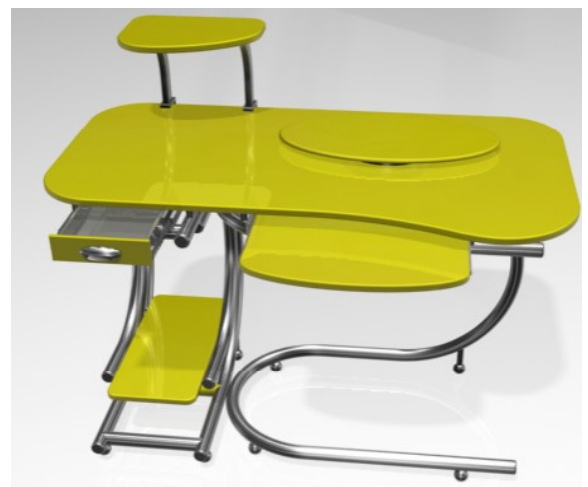

Fig. (5). Solution of yellow glass. 


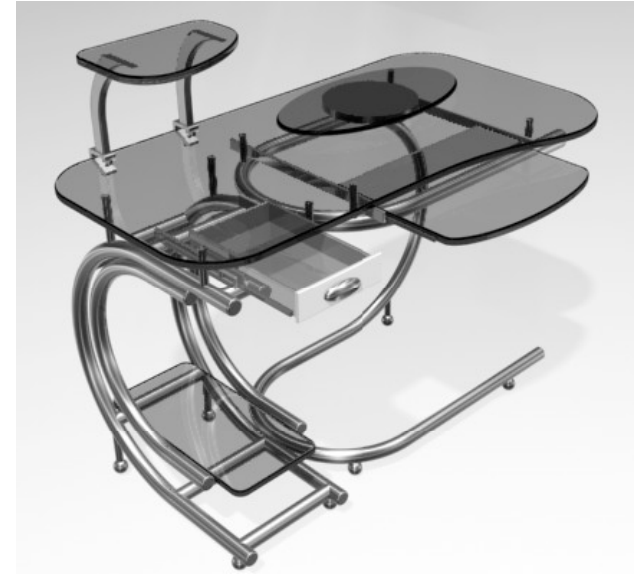

Fig. (6). Solution of transparent glass.

\section{CONCLUSION}

"People-oriented" is modern industrial design advanced concepts. The design aspects of structure size in determining effective combination of ergonomics and human basic dimensions as design basis, in the process of aesthetic and mechanical design combined with full application of principles of ergonomics to improve product agreeableness, everywhere embodies the human design. Correction and increased functionality of desktop shapes effectively alleviate the way people work, learn physical pressure. Computer desk in this design has compact structure, beautiful shape, which brings the users convenience and comfort.

\section{CONFLICT OF INTEREST}

The authors confirm that this article content has no conflict of interest.

\section{ACKNOWLEDGEMENTS}

Declared none.

\section{REFERENCES}

[1] Wei Li etc. Color composition. Beijing: Chemical industry press, 2003.12. pp39-43.

[2] Hongliang Zuo. Homework space color design based on ergonomics. Packaging engineering, 2005,25.pp121-126.

[3] Yulan Ding. Ergonomics.Beijing: Beijing institute of technology press, 2007, pp116-117.

[4] New mechanical engineering technical manual code to compile. New mechanical engineering technical manuals. Beijing: Beijing economic daily press, 1995.5, pp94-271.

[5] Mechanical design manual. Joint code to compile. Mechanical design manual(the days of the second volume). Second edition. Beijing: Chemical industry press,1987.12, pp790-967.

[6] Handbook of mechanical engineering. Electrical engineering manual editorial board. Mechanical engineering manual/mechanical design (3).Beijing: Machinery industry press. 1996. pp32-189.

[7] The Chinese academy of agricultural machinery chemical science. Practical mechanical design manual/part ii. Beijing: China agricultural machinery press. In July, 1985. pp888 - 891.

[8] Tao Liu. Industrial product modeling design. Beijing: metallurgical industry press, March 2008. pp6 - 11 .

[9] Shaoqiang Ning, Kebing Tang. Humanized design of products. Journal of guilin institute of electronics industry, 2003,23. pp63 671.

[10] Hao Yuan etc. Computer aided industrial design. Beijing: chemical industry press, in April 2004. pp 20-30.

Received: September 16, 2014

Revised: December 23, 2014

Accepted: December 31,2014

(C) Du et al.; Licensee Bentham Open.

This is an open access article licensed under the terms of the Creative Commons Attribution Non-Commercial License (http://creativecommons.org/licenses/by-nc/3.0/) which permits unrestricted, non-commercial use, distribution and reproduction in any medium, provided the work is properly cited. 